\section{Appearance of $\beta$-dystroglycan precedes the formation of glio-vascular end-feet in developing rat brain}

\author{
Mihály Kálmán, Erzsébet Oszwald, \\ István Adorján $\$$
}

Department of Anatomy, Histology and Embryology, Semmelweis University, Budapest, Hungary

\$Present address: Department of Physiology, Anatomy and Genetics, University of Oxford, UK

\begin{abstract}
Dystroglycan has an important role in binding of perivascular glial end-feet to the basal lamina. Its $\beta$-subunit is localized in the glial end-feet. The investigation period lasted from $\mathrm{E}$ (embryonic day) 12 to E20. Laminin and $\beta$-dystroglycan were detected by immunohistochemistry, the glial localization of the latter one was supported by electron microscopy. The immature glial structures were visualized by the immunostaining of nestin. The $\beta$-dystroglycan immunoreactivity appeared at E16 following the laminin of basal lamina but preceding the perivascular processes of radial glia (E18) and astrocyte-like cells (E20). It occurred in cell bodies which attached to the vessels directly but not with vascular processes and end-feet. The presence of $\beta$-dystroglycan in such immature cells may promote their differentiation to perivascular astrocytes and influence the formation of the glio-vascular processes.
\end{abstract}

\section{Introduction}

The dystroglycan complex has an important role in glio-vascular coupling. ${ }^{1}$ It consists of an $\alpha$ - and a $\beta$-subunit. The $\alpha$ dystroglycan subunit is extracellular and binds laminin and other components of basal lamina. The $\beta$-dystroglycan subunit is a trans-membrane protein, which anchors the $\alpha$-dystroglycan to the cell membrane. Its immunoreactivity delineates the brain vessels, ${ }^{2,3}$ but it is localized in the perivascular glial end-feet. ${ }^{1,4,5}$ The intracellular end of $\beta$-dystroglycan forms a complex with dystrophin and other proteins. The complex anchors aquaporin 4 water channel, Kir 4.1 channel for potassium and signaling systems..$^{1,6}$
The scope of the study was the appearance of $\beta$-dystroglycan along the developing rat cerebral vessels continuing our other studies on cerebrovascular dystroglycan. The investigation period lasted from E (embryonic day) 12 to E20. The immunofluorescent localization of $\beta$-dystroglycan was completed with electron microscopical immunoperoxidase reaction. Immunostaining for nestin was used to visualize the immature glia. ${ }^{7-9}$ The whole prosencephalon was studied but photomicrographs were taken from the dorsoparietal pallium.

\section{Materials and Methods}

\section{Animals}

All procedures were in accordance with the Committee on the Care and Use of Laboratory Animals at the Semmelweis University (22.1/3491/003/2008) and the European Union Directive (EU Directive 2010/63/EU). Vaginal smears were prepared from female albino Wistar rats mated with males overnight. The day of sperma positivity was considered as E0. At E12, 14, 16, 18 and 20 embryos were removed by Caesarian section from different mothers (2-2 at every ages) in deep ketaminexylazine narcosis $(80$ and $20 \mathrm{mg} / \mathrm{kg}$ body weight, respectively, intramuscularly).

\section{Fixation and sectioning}

The embryo brains were fixed by immersion in $4 \%$ paraformaldehyde in 0.1 $\mathrm{M}$ phosphate buffer ( $\mathrm{pH}$ 7.4) for a week. Then they were embedded into agarose, coronal sections $(50 \mu \mathrm{m})$ were cut with Vibratome (Leica VT 1000S) and rinsed in phosphate buffered saline (PBS, SigmaAldrich, St. Louis, MO, USA) overnight.

\section{Fluorescent immunohistochemistry}

Floating sections were pretreated with $20 \%$ normal goat serum diluted in PBS (90 min). Every steps were followed by rinse in PBS (30 min). The sections were incubated with primary antibodies (Table 1 ) for $40 \mathrm{~h}$ at $4^{\circ} \mathrm{C}$ (all the other procedures occurred at room temperature). The fluorescent secondary antibodies were produced by Jackson Immunoresearch Lab. Inc. (West Grove, PA, USA): monoclonal anti-mouse labeled with $\mathrm{Cy}^{3}(550 / 570 \mathrm{~nm}$, red) and polyclonal anti-rabbit labeled with FITC (492/520 nm, green). They were applied for $3 \mathrm{~h}$. Control sections were treated similarly but without primary antibodies. No structure-bound fluorescent labeling was observed in these specimens.
Correspondence: Prof. Mihály Kálmán, Department of Anatomy, Histology and Embryology, Semmelweis University, Tuzolto 58, H-1094, Budapest, Hungary.

E-mail: kalmanprof@gmail.com

Key words: Brain development; dystroglycan glial end-feet; glio-vascular; nestin.

Conflict of interest: The authors declare that there is no actual or potential conflict of interest.

Contributions: MK, experimental design, manuscript drafting: IA, confocal microscopy; EO, electron microscopy. All authors have approved the article and agreed the submission.

Acknowledgments: This study was supported by the Department of Anatomy, Histology and Embryology, Semmelweis University, Budapest, Hungary. The technical assistance of A. Öz, S. Deák and Z. Gróti is highly appreciated.

Received for publication: 21 February 2018 Accepted for publication: 3 May 2018.

This work is licensed under a Creative Commons Attribution-NonCommercial 4.0 International License (CC BY-NC 4.0).

(C) Copyright M. Kálmán et al., 2018

Licensee PAGEPress, Italy

European Journal of Histochemistry 2018; 62:2908 doi:10.4081/ejh.2018.2908

\section{Fluorescent microscopy and digital} imaging

High-power photomicrographs were taken with a Radiance-2100 (BioRad, Hercules, CA, USA) confocal laser scanning microscope (488 nm, argon laser and $543 \mathrm{~nm}, \mathrm{He} / \mathrm{Ne}$ laser) whereas low-power ones with a DP50 digital camera mounted on an Olympus BX-51 microscope with Epi-Filter Blocks, Texas Red and FITC (both microscopes from Olympus Optical Co. Ltd, Tokyo, Japan). Digital images were processed using Photoshop 9.2 software (Adobe Systems, Mountain View, CA, USA)

\section{Preembedding electron microscopic immunohistochemistry}

In this case $0.5 \%$ glutaraldehyde was added to the fixative solution. Immunoperoxidase reaction against $\beta$-dystroglycan was performed according to the avidinbiotinylated peroxidase (ABC) method. Endogenous peroxidase was inactivated with $3 \% \mathrm{H}_{2} \mathrm{O}_{2}$ in PBS (5 min) followed by an intense rinse in PBS (30 $\mathrm{min}$ at room temperature). Incubations with $20 \%$ nor- 
mal goat serum and primary anti $\beta$-dystroglycan were carried out as above except for that Triton X-100 detergent was reduced to $0.1 \%$. The procedure continued by applying biotinylated anti-mouse serum $(1: 100)$ followed by the avidin-biotinylated peroxidase complex (both from Vector Laboratories, Burlingame, CA, USA). Both incubations lasted for $90 \mathrm{~min}$. To visualize the reaction product $0.05 \% 3,3$, diaminobenzidine-tetrahydrochloride (DAB) and $0.01 \% \mathrm{H}_{2} \mathrm{O}_{2}$ in Tris- $\mathrm{HCl}$ buffer (0.05 M, pH 7.4) were used. The reaction was stopped at visual color control by replacing the solution with PBS.

\section{Electron microscopic investigation}

Following the immunoreactions areas of the sections were cut under light microscope. Following osmification with $1 \%$ osmium tetroxide solution in phosphate buffer $(0.1 \mathrm{M}, \mathrm{pH} 7.4,30 \mathrm{~min})$ the tissue pieces were rinsed in phosphate buffer and dehydrated through a graded series up to absolute ethanol. Following immersion in propylene oxyde $(10 \mathrm{~min})$ the tissue pieces were embedded into epoxy resin (Durcupan, Fluka). Semithin sections were cut with a Reichert Ultracut S ultramicrotome; the proper areas were selected, and the samples were adequately trimmed. Ultrathin sections were prepared with the same ultramicrotome. The photomicrographs were taken by a JEOL 100B electron microscope (at $80 \mathrm{kV}$ ) equipped with a Sys Morada digital camera.

\section{Results}

\section{$\beta$-dystroglycan immunoreactivity delineates vessels by $\mathrm{E} 16$}

At the beginning of the period investigated, at E12-14, no vascular $\beta$-dystroglycan immunoreactivity was found (Figure 1a) whereas the laminin immunoreactivity delineated the brain vasculature (Figure 1b). Most vessels oriented radially interconnected loosely by vessels parallel with the pial surface. The vascular $\beta$-dystroglycan immunoreactivity appeared by E16. The vascular pattern was identical with that seen in the case of laminin (Figure $1 \mathrm{c}, \mathrm{d}$ ).

Electron microscopic investigation revealed that the product of immunohistochemical reaction against $\beta$-dystroglycan was localized in perivascular cell bodies which contacted the vessels directly, cellto-cell. Since nuclei were clearly visible in them, they were not end-feet but cell bodies (Figure 1 e,f).

\section{The appearance of glial end-feet}

Nestin immunoreactivity visualized a dense system of radial fibers. At E16 laminin-immunoreactive vessels only formed scarce side-to-side (en passant) contacts between radial glia and vessels were observed but no glial processes terminated with end-feet on vessels (Figure 2a). At E18 however, glial processes formed endings along the vessels (Figure 2 b,c). By E20 the radial glial system became more complex, the vascular processes were generalized and several end-feet contacted the vessels. Nestin immunostaining already revealed scarce astrocyte-like elements which also formed vessel-contact processes (Figure 2d). At E20 electron microscopy also revealed small profiles (Figure 2e) interposed between the cell bodies. They contained no nuclei and seemed to be endings of glial processes. They also contained $\beta$-dystroglycan immunoperoxidase reaction product.

\section{Discussion}

\section{$\beta$-dystroglycan appears later than laminin and other basal lamina components}

Cerebrovascular laminin immunoreactivity was found from E10 by Risau and Lemmon. ${ }^{10}$ The $\beta$-dystroglycan immunoreactivity appears considerably later. In the absence of dystroglycan, however, the laminin-binding task may also be taken by integrins. ${ }^{11,12}$ It is to be noted that according to recent opinions the main task of the dystroglycan complex is to anchor aquaporin 4 and other channels and receptors in the glial membrane where it contacts basal lamina rather than to fix the cells them- selves. ${ }^{13,14}$ Kir4.1 protein was detected at E20. ${ }^{15}$ The appearance of aquaporin 4 is dated rather variously, from E16 ${ }^{16,17}$ to E21. ${ }^{18}$

\section{$\beta$-dystroglycan immunoreactivity appears in perivascular cells lack- ing end-feet}

Some previous studies described that the investment of blood vessels began by vessel-contact cells showing no multibranched morphology. ${ }^{9,19,20}$ Whether these cells had been committed to astrocyte fate when contacted vessels or just the contact committed them it is not clear. They contained neither nestin nor vimentin, which only appeared during the formation of their multibranchial astrocyte shape. Zerlin et al. ${ }^{9}$ supposed that vessels provide signals to promote the elaboration of astrocyte shape. Endothelium-produced bone morphogenetic proteins (BMP) have such effect. ${ }^{21}$ Endothelium-produced leukemia inhibitory factor (LIF) promotes astrocyte fate to neuronal one. ${ }^{20,22}$ Weidenfeller et $a l .{ }^{23}$ found that vessel-contact progenitor cells developed most frequently to astrocytes in cultures. For a recent review see Goldman. ${ }^{24}$

Our observations on the process formation are in accordance with the former ones which found vascular processes of radial glia from E17 and cells resembling astrocytes from E19-20..$^{25-27}$

\section{Dystroglycan and astrocyte differentation}

The appearance of $\beta$-dystroglycan is a step of differentiation of perivascular astrocytes, since dystroglycan is a characteristic molecule of these cells. ${ }^{1}$ The dystroglycan complex contains GRB2 (growth factor receptor binding protein). ${ }^{6}$ It promotes the action of LIF; 22 its absence restricts astrocyte differentiation. ${ }^{28}$ The early presence of $\beta$-dystroglycan suggests that the vascular processes do not extend from the cell body to the vessels rather they lengthen as the cell bodies are 'pushed' apart by other cells inserted. The dystroglycan-containing parts remain attached to the vessels and transform to end-feet. This type of transition from round vessel-contact cells to end-feet

Table 1. Primary antibodies applied in the study.

\begin{tabular}{|c|c|c|c|c|c|}
\hline Against & Host & Company & Code number & Dilution $^{\circ}$ & Final concentration $(\mu g / m L)$ \\
\hline$\beta$-dystroglycan & Mouse* & Novocastra, Newcastle-on-Tyne, UK & ncl-b-dg & $1: 100$ & 0.19 \\
\hline Laminin 1 & Rabbit** & Sigma, San Louis, MO, USA & 19393 & $1: 100$ & 5 \\
\hline Nestin & Mouse* & Millipore, Temecula, CA, USA & MAB-353 & $1: 1000$ & 1 \\
\hline
\end{tabular}

*Monoclonal; ** polyclonal; ${ }^{*}$ in PBS with $0.5 \%$ Triton X-100 and 0.01\% sodium azide. 
bearing ones is demonstrated by Engelhardt ${ }^{29}$ (see her Figure 3). Knockouts of $\beta$-dystroglycan in the GFAP-expressing structures had a detrimental effect on the formation of pial astroglial end-feet. ${ }^{30-32}$ Vascular end-feet, however, were not investigated. In conclusion, $\beta$-dystroglycan already appears in immature perivascular cells and may promote their differentiation to astrocytes and influence the formation of glio-vascular processes.
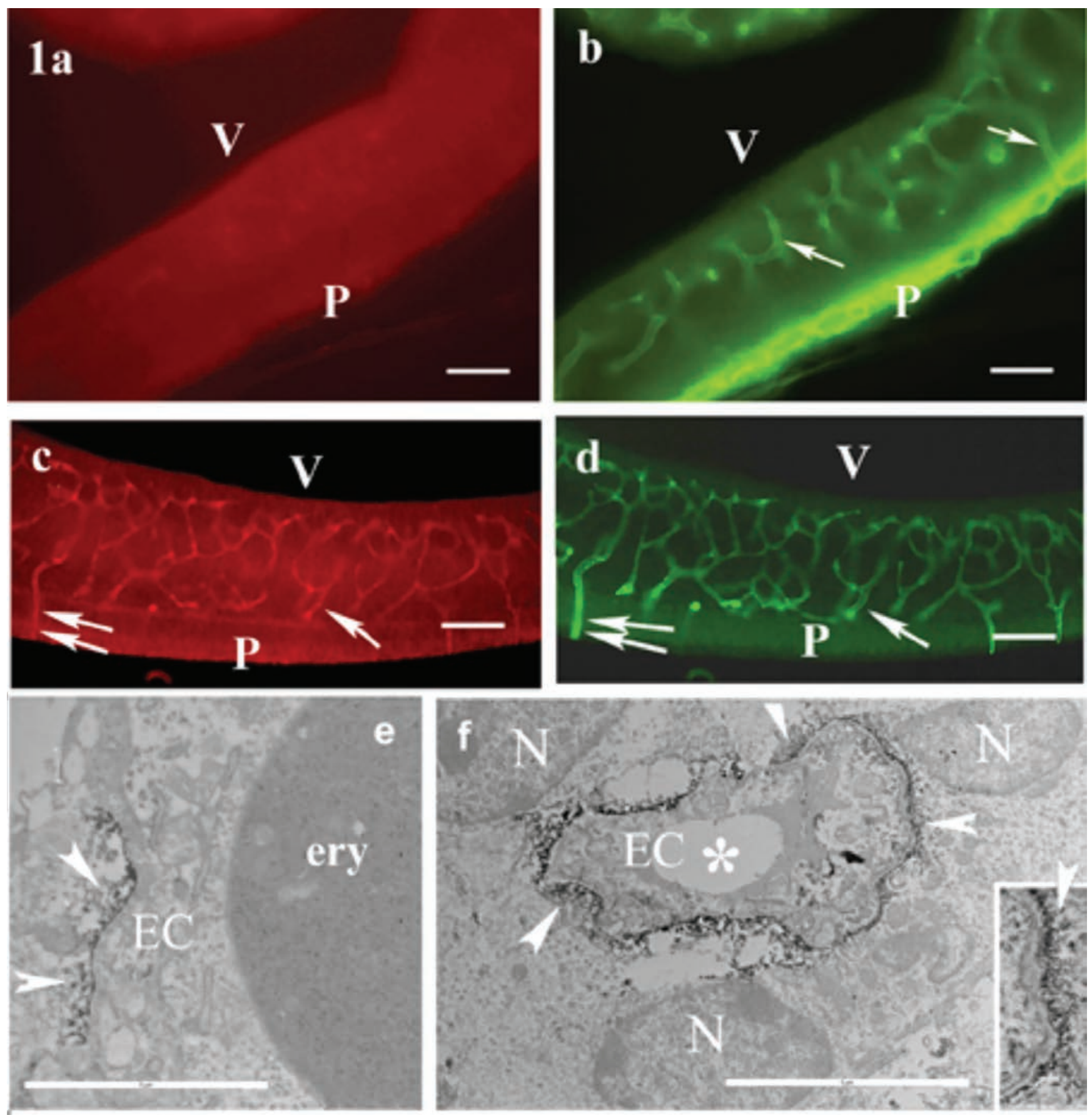

Figure 1. Appearance of $\beta$-dystroglycan immunoreactivity delineates vessels. a,b) E14 (embryonic day), rat dorsolateral pallium, double immunostaining for $\beta$-dystroglycan and laminin; laminin immunostaining visualizes the cerebral vasculature and the pial (P) basal lamina; arrows and double arrows label identical points in the parallel photos; V, ventricle. c,d) E16, double immunostaining for $\beta$-dystroglycan and laminin; both $\beta$-dystroglycan and laminin immunoreactivities delineate the same vessels (arrows and double arrows label identical points in the parallel photos); P, pial surface; $\mathrm{V}$, ventricle. e,f) E16, rat dorsolateral pallium, electron microscopic immunoperoxidase reaction for $\beta$-dystroglycan; the $\beta$-dystroglycan immunoreactivity (arrowheads) is localized in vessel-contact cell bodies; asterisks, capillary lumen; N, nucleus; EC, endothelial cell; ery, erythrocyte. Inset: an enlarged detail pointed by arrow at the right border of the vessel. Scale bars: a-d) $60 \mu \mathrm{m}$; e,f) $5 \mu \mathrm{m}$; inset, $2 \mu \mathrm{m}$. 

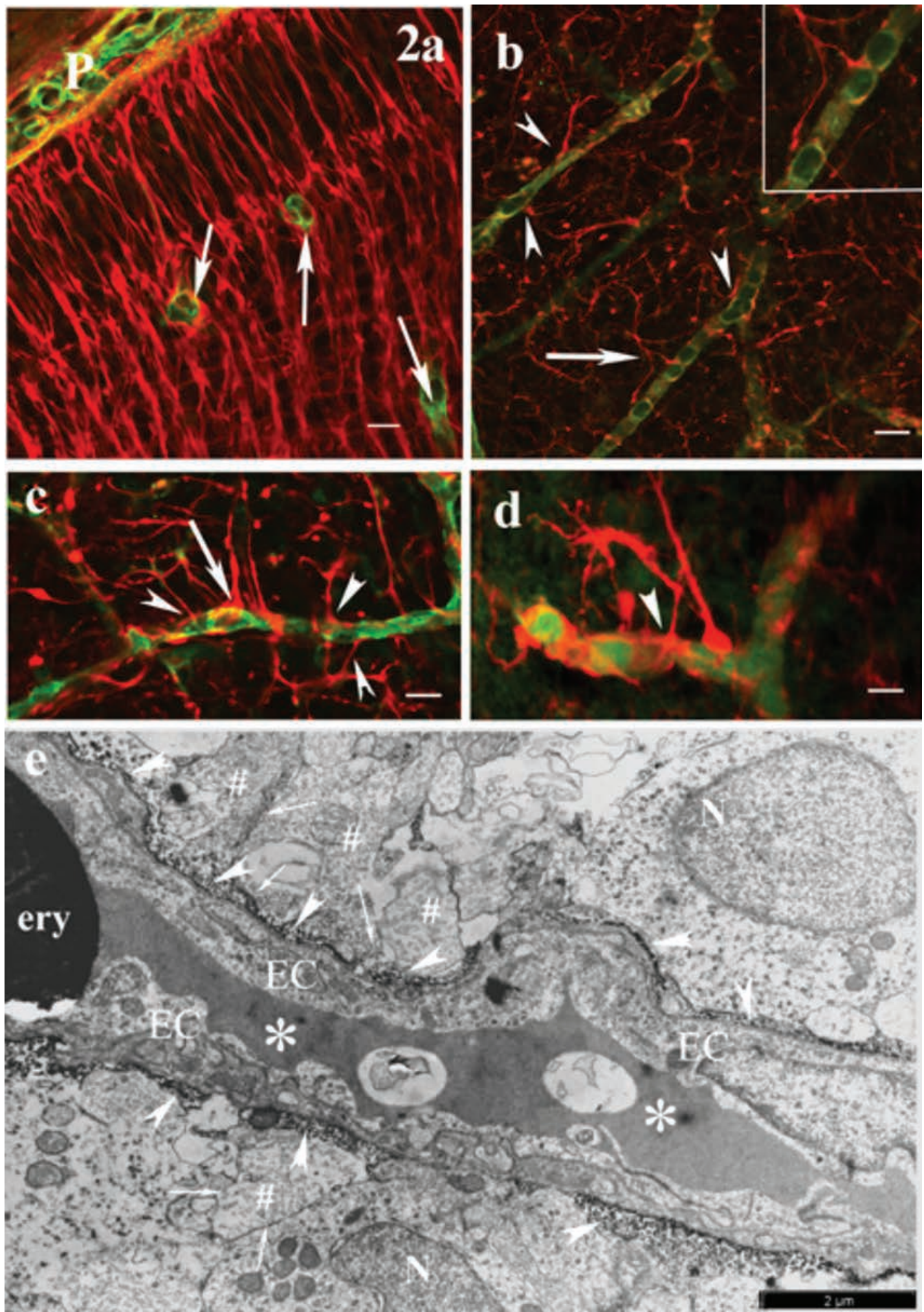

Figure 2. Appearance of glial vascular end-feet. Confocal photomicrographs following double labeling of nestin (red) and laminin (green). a) E16: despite of the vicinity of vessels, no glial end-feet have been visualized; arrows point to laminin-immunoreactive vessels; P, pial surface; scale bar: $20 \mu \mathrm{m}$. b) E18: several endings of glial processes on vessels (arrowheads). Arrow points a bifurcating process with two endings (see enlarged in inset); scale bar: $30 \mu \mathrm{m}$; inset: $20 \mu \mathrm{m}$. c) E18: large end-feet-like widenings at the ends of two processes (arrow) on a vessel; the close contacts (yellow color), however, have not yet been generalized; arrowheads point to lesser end-feet of other glial processes on the vessel; scale bar: $20 \mu \mathrm{m}$. d) E20: nestin-immunoreactive astrocyte-like structure extends a process with endfoot (arrowhead) to a vessel; scale bar: $10 \mu \mathrm{m}$. e) A vessel at E20, electron microscopic immunoperoxidase reaction for $\beta$-dystroglycan (arrowheads); besides the nucleus $(\mathrm{N})$-containing cell bodies there are small profiles: endings of glial processes (\#; arrows: their cell borders); asterisks: capillary lumen; EC, endothelial cell; ery, erythrocyte; scale bar: $2 \mu \mathrm{m}$. 


\section{References}

1. Wolburg H, Noell S, Mack A WolburgBuchholz K Fallier-Becker P. Brain endothelial cells and the glio-vascular complex. Cell Tissue Res 2009;335:7596.

2. Zaccaria ML, Di Tommaso F, Brancaccio A, Paggi P, Petrucci TC. Dystroglycan distribution in adult mouse brain: a light and electron microscopic study. Neuroscience 2001; 104:311-24.

3. Szabó A, Kálmán M. Post traumatic lesion absence of $\beta$-dystroglycan immunopositivity in brain vessels coincides with the glial reaction and the immunoreactivity of vascular laminin. Curr Neurovasc Res 2008;5:206-13.

4. Tian M, Jacobson C, Gee SH, Campbell KP, Carbonetto S, Jucker M. Dystroglycan in the cerebellum is a laminin a2-chain binding protein at the glial-vascular interface and is expressed in Purkinje cells. Eur J Neurosci 1996; 8:2739-47.

5. Haenggi T, Fritschy JM. Role of dystrophin and utrophin for assembly and function of the dystrophin glycoprotein complex in non-muscle tissue. Cell Mol Life Sci 2006;63:1614-31.

6 . Winder SJ. The complexities of dystroglycan. Trends Biochem Sci 2001;26: 118-24.

7. Hockfield S, McKay RDG. Identification of major cell classes in the developing mammalian nervous system. J Neurosci 1985;12:3310-28.

8. Kálmán M, Ajtai BM. A comparison of intermediate filament markers for presumtive astroglia in the developing rat neocortex: immunostaining against nestin reveals more detail than GFAP or vimentin. Int J Dev Neurosci 2001;19: 101-8.

9. Zerlin M, Levison SW, Goldman JE. Early patterns of migration morphogenesis and intermediate filament expression of subventricular zone cells in the postnatal rat forebrain. J Neurosci 1995; 15:7238-49

10. Risau W, Lemmon V. Changes in the vascular extracellular matrix during embryonic vasculogenesis and angiogenesis. Dev Biol 1988;125:441-50.
11. Del Zoppo GJ, Milner R. Integrinmatrix interactions in cerebral microvasculature. Atheroscler Thromb Vasc Biol 2006;26:1966-75.

12. Milner R, Campbell IL. Developmental regulation of $\beta 1$ integrins during angiogenesis in the central nervous system. Mol Cell Neurosci 2002;20:616-26.

13. Guadagno E, Moukhles K. Laminininduced aggregation of the inwardly potassium channel Kir 41 and the water permeable channel AQP4 via a dystroglycan-containing complex in astrocytes. Glia 2004;47:138-49.

14. Noel G, Tham DKL, Moukhles H. Interdependence of laminin-mediated clustering of lipid rafts and the dystrophin complexin astrocytes. J Biol Chem 2009;284:19694-704.

15. Moroni RF, Inverardi F, Regondi MC, Pennacchio P, Frassoni C. Developmental expression of Kir4.1 in astrocytes and oligodendrocytes of rat somatosensory cortex and hippocampus. Int J Dev Neurosci 2015;47:198205.

16. Goren O, Adorján I, Kálmán M. Heterogeneous occurrence of aquaporin-4 in the circumventricular organs in rat and chicken. Anat Embryol 2006;211:155-72.

17. Fallier-Becker P, Vollmer JP, Bauer HC, Noell S, Wolburg H, Mack AF. Onset of aquaporin-4 expression in the developing mouse brain. Int J Dev Neurosci 2014;36:81-9.

18. Daneman R, Zhou L, Kebede AA, Barres BA. Pericytes are required for blood-brain barrier integrity during embryogenesis. Nature 2010;468:5626.

19. Zerlin M, Goldman J. Interaction between glial progenitors and blood vessels during early postnatal corticogenesis: blood vessel contact represents an early stage of astrocyte differentiation. J Comp Neurol 1997;387:537-46.

20. Mi H, Haeberle H, Barres BA. Induction of astrocyte differentiation by endothelial cells. J Neurosci 2001;21: 1538-47.

21. Imura T, Tane K, Toyoda N, Fushiki S. Endothelial cell-derived bone morphogenetic proteins regulate glial differentiation of cortical progenitors. Eur J Neurosci 2008;27:1596-606.
22. Viti J, Feathers A, Phillips J, Lillien L. Epidermal growth factor receptors control competence to interpret leukemia inhibitory factor as an astrocyte inducer in developing cortex. J Neurosci 203; 23:3385-93.

23. Weidenfeller C, Svendsen CN, Shusta EV. Differentiating embryonic neural progenitor cells induce blood- brain barrier properties. J Neurochem 2007; 101:555-65.

24. Goldman J. Astrocyte development. In: Kettenmann H, Ransom BR, eds. Neuroglia, 3rd Edition. Oxford, Oxford University Press, 2013, pp 137-47.

25. Fedoroff S. Prenatal ontogenesis of astrocytes. In: Feodoroff S, Vernadakis A, eds. Astrocytes. Academic Press; New York; 1986; pp. 35-74.

26. Takahashi T, Misson J-P, Caviness VS Jr. Glial process elongation and branching in the developing murine neocortex, A qualitative and quantitative immunohistochemical analysis. J Comp Neurol 1990;302:15-28.

27. Misson JP, Takahashi T, Caviness VS Jr. Ontogeny of radial and other astroglial cells in murine cerebral cortex. Glia 1991;4:138-48.

28. Fujimoto I, Hasegawa K, Fujiwara K, Yamada M, Yoshikawa K. Necdin controls EGFR signaling linked to astrocyte differentiation in primary cortical progenitor cells. Cell Signal 2016;28:94-107.

29. Engelhardt B. Development of the blood-brain barrier. Cell Tissue Res 2003;314:119-29.

30. Moore SA, Saito F, Chen J, Michele ED, Henry MD, Messing A, et al. Deletion of brain dystroglycan recapitulates aspects of congenital muscular dystrophy. Nature 2002;418:422-5.

31. Noell S, Wolburg-Buchholz K, Mack AF, Beedl AM, Satz JS, Campbell KP, et al. Evidence for a role of dystroglycan regulating the membrane architecture of astroglial endfeet. Eur J Neurosci 2011;33:2179-86.

32. Myshrall TD, Moore SA, Ostendorf AP, Satz JS, Kowalczyk T, Nguyen H, et al. Dystroglycan is required for pial basement membrane integrity. J Neuropathol Exp Neurol 2012;71:104763. 